\title{
THE MASS BALANCE OF BLUE GLACIER, WASHINGTON, U.S.A.
}

\section{6-1986}

\section{(Abstract)}

\author{
by
}

Richard L. Armstrong

(CIRES and World Data Center A for Glaciology, Campus Box 449, University of Colorado, Boulder, CO 80309, U.S.A.)

Mass-balance data for Blue Glacier are presented for the 31-year period 1956-86. The glacier location is strongly maritime with annual precipitation of 3500 to $5000 \mathrm{~mm}$, most of which falls as winter snow. The low elevation of the glacier results in large amounts of summer ablation and thus significant annual mass exchange. Blue Glacier has been in approximate equilibrium with recent climate during the past 30 years with a slightly positive mean annual net balance of $0.3 \mathrm{~m}$ and a terminus advance of $150 \mathrm{~m}$. Comparison with other glaciers in western North America indicates that this pattern of mass increase in response to recent climate is not typical but may be specific to a maritime location.
Due to heavy amounts of winter snowfall, an accumulation area ratio of only 0.5 is sufficient to maintain a zero balance on Blue Glacier. A strong gradient of increasing snowfall with elevation contributes to a linear relationship between net balance and elevation throughout the total altitude range of the glacier. This relationship is consistent over the period of record and is not dependent on an overall net positive balance, as the pattern persists even during periods of strongly negative mass balance. A relationship between measured mass balance and equilibriumline altitude provides a reasonable method to compute mass balance.

\section{REACTION OF THE HEAT REGIME OF ANTARCTIC ICE SHEET INLAND REGIONS ON LONG-TERM CHANGES OF CLIMATE \\ (Abstract)}

by

Vitaly Barbash

(Garden Apartments, D-11, Kutztown, PA 19530, U.S.A.)

\begin{abstract}
A nonstationary mathematical model of thermics and dynamics of the Antarctic ice sheet has been developed, taking into consideration the influence of long-term changes of climate.

The influence of climatic variations during the last 100000 years on the temperature field within the ice sheet has been analysed. Information about climatic changes is based on paleographic data and isotope analyses of ice samples from bore holes at Vostok and Byrd stations.

The input data used include results from field surveys of accumulation, temperatures of upper surface, relief of
\end{abstract}

the base and thickness of the ice sheet along the flowlines in the western and eastern parts of the ice sheet, as well as experimental data on ice rheology.

The computations show that traces of the climatic minimum that took place about 18000 years ago are found in the temperature field of the Antarctic ice sheet.

The model developed has proved that warming of climate due to the "greenhouse effect" leads to significant changes in the thermal regime in the upper parts of the ice sheet, but will not lead to conditions threatening bottom layers. 